\title{
ILEGALIDAD APARENTE O VIOLACIÓN PERMANENTE: \\ Los derechos de autor y las tecnologías P2P
}

Édgar Iván León Robayo

Eduardo Varela Pezzano

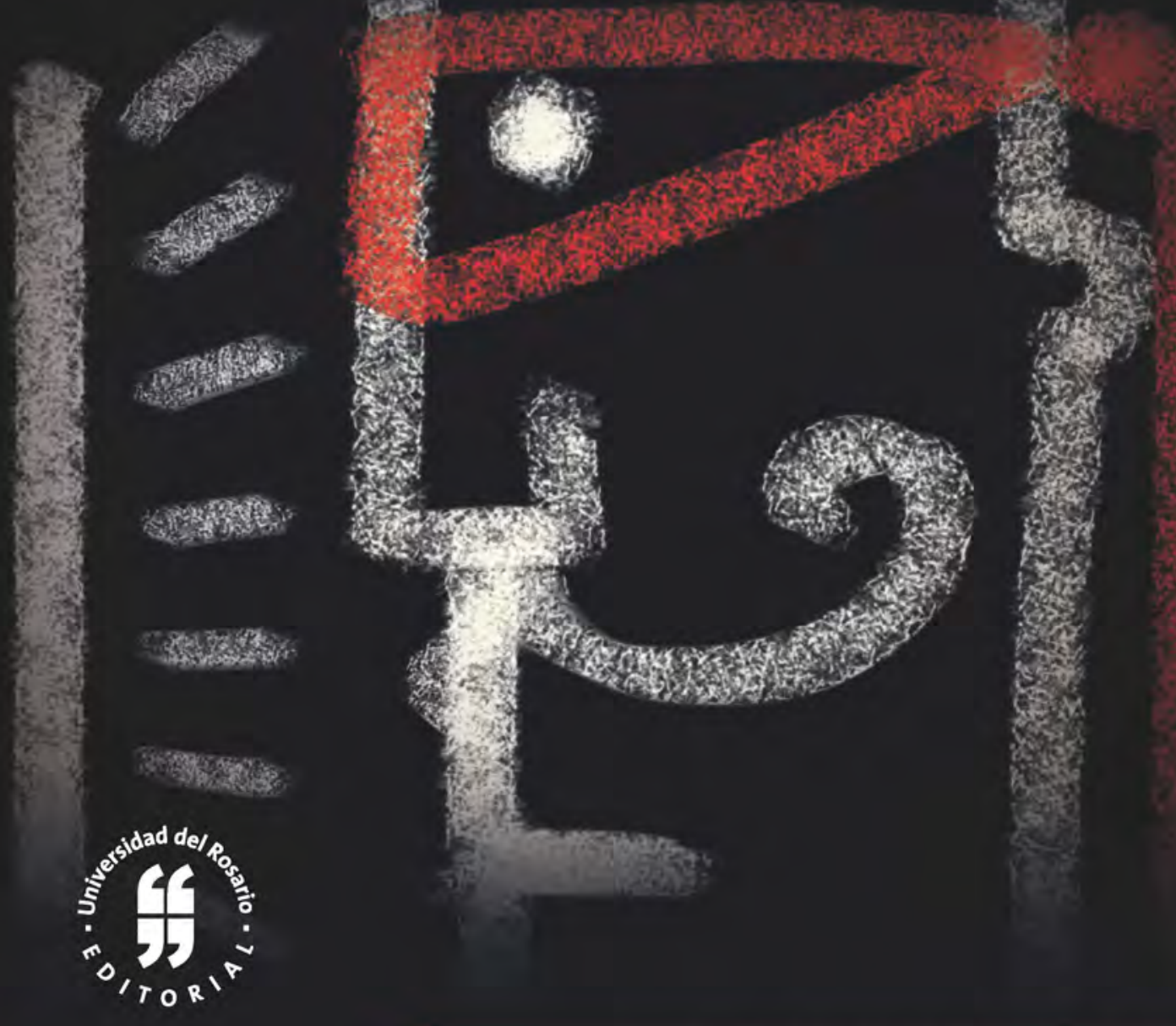




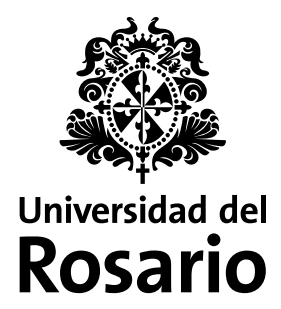



Ilegalidad aparente o violación permanente: los derechos de autor y las tecnologías P2P 
León Robayo, Édgar Iván

Ilegalidad aparente o violación permanente: los derechos de autor y las tecnologías P2P / Édgar Iván León Robayo, Eduardo Varela Pezzano. - Bogotá: Editorial Universidad del Rosario, Facultad de Jurisprudencia, 2015. $\mathrm{x}, 100$ páginas. - (Colección Textos de Jurisprudencia)

Incluye referencias bibliográficas.

ISBN: 978-958-738-641-7 (impreso)

ISBN: 978-958-738-642-4 (digital)

Derechos de autor / Redes de computadores - Aspectos jurídicos / P2P (Redes de computadores) - Historia / Internet (Red de computadores) - Aspectos jurídicos / I. Varela Pezzano, Eduardo Secondo / II. Universidad del Rosario, Facultad de Jurisprudencia / III. Título / IV. Serie.

$346.0482 \quad$ SCDD 20

Catalogación en la fuente - Universidad del Rosario. Biblioteca jda Julio 23 de 2015

Hecho el depósito legal que marca el Decreto 460 de 1995 


\section{Ilegalidad aparente o violación permanente: los derechos de autor y las tecnologías P2P}

Édgar Iván León Robayo

Eduardo Varela Pezzano 
Colección Textos de Jurisprudencia

(C) Editorial Universidad del Rosario

(C) Universidad del Rosario, Facultad de Jurisprudencia

(C) Édgar Iván León Robayo, Eduardo Varela Pezzano

Editorial Universidad del Rosario

Carrera 7 No 12B-41, oficina 501 • Teléfono 2970200

editorial.urosario.edu.co
Primera edición: Bogotá D. C., septiembre del 2015

ISBN: 978-958-738-641-7 (impreso)

ISBN: 978-958-738-642-4 (digital)

Coordinación editorial: Editorial Universidad del Rosario

Corrección de estilo: Liliana Ortiz Fonseca

Diseño de cubierta: Miguel Ramírez, Kilka DG

Diagramación: Martha Echeverry

Impresión: Digiprint

Impreso y hecho en Colombia

Printed and made in Colombia

Fecha de evaluación: 28 de mayo de 2015

Fecha de aceptación: 17 de junio de 2015

Todos los derechos reservados. Esta obra no puede ser reproducida sin el permiso previo por escrito de la Editorial Universidad del Rosario. 


\section{Contenido}

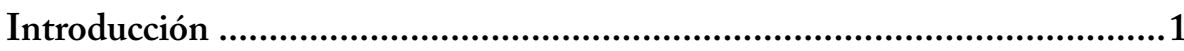

\section{Capítulo 1}

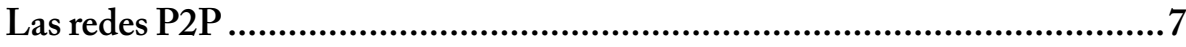

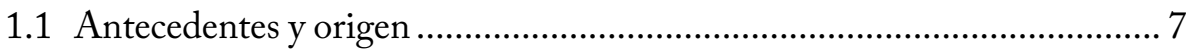

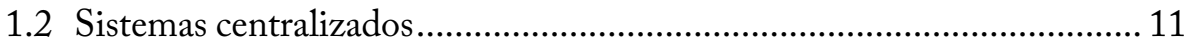

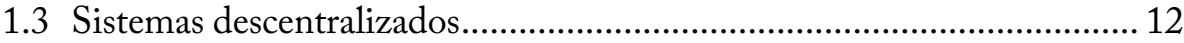

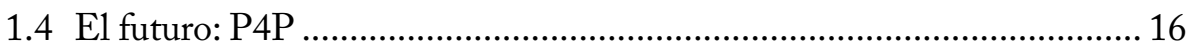

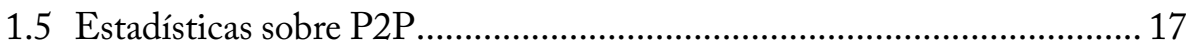

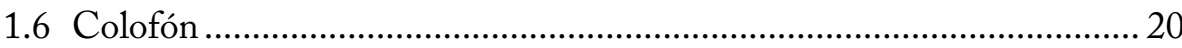

\section{Capítulo 2}

La infracción al derecho de autor y al copyright ...........................................21

2.1 Responsabilidad de las empresas P2P .................................................. 21

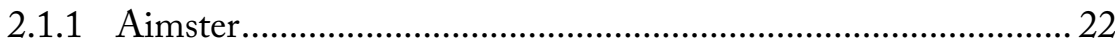

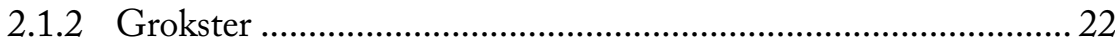

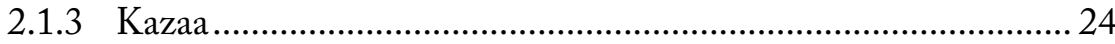

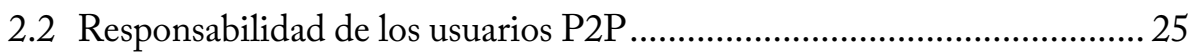

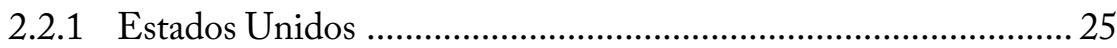

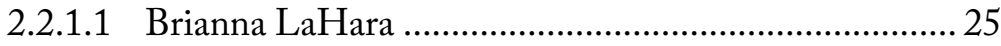

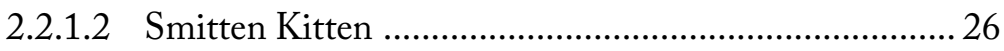

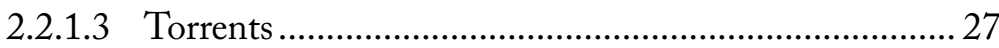

2.2.1.4 Lewan v. Sharman ........................................................ 27

2.2.1.5 El caso Jammie Thomas o la primera condena por infracción directa en

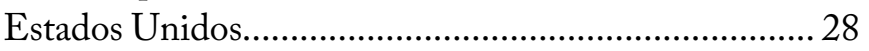

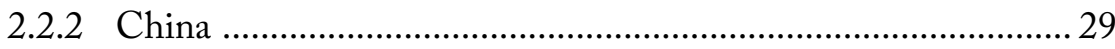

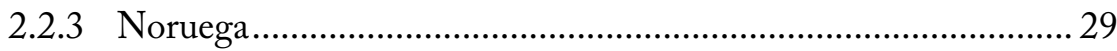

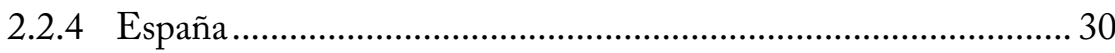




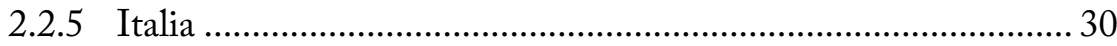

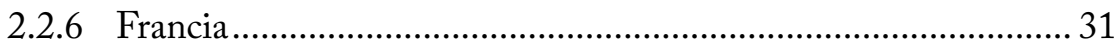

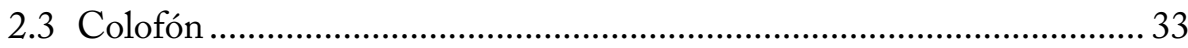

\section{Capítulo 3}

Los derechos a la intimidad y hábeas data

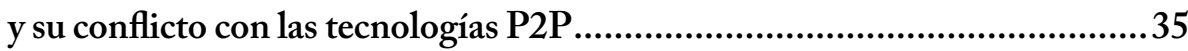

3.1 Normativas generales de protección a la privacidad

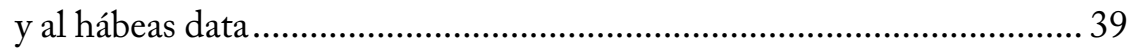

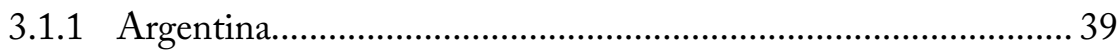

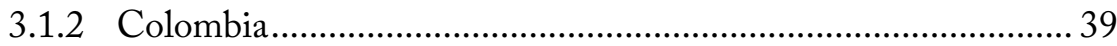

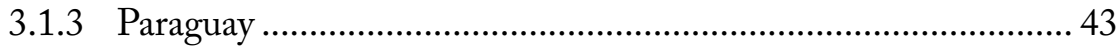

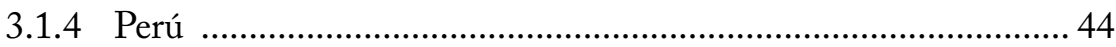

3.2 Decisiones judiciales sobre la pugna entre la privacidad $\mathrm{y}$ los derechos de autor por la utilización de tecnologías $\mathrm{P} 2 \mathrm{P}$.................. 45

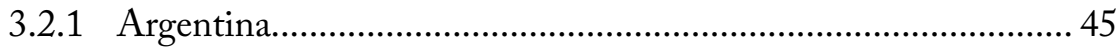

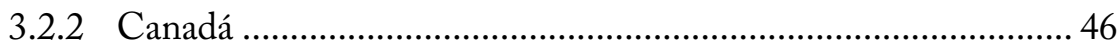

3.2.2.1 вMG Canada Inc. v. John Doe ...................................... 47

3.2.2.2 Socan v. CAIP............................................................... 47

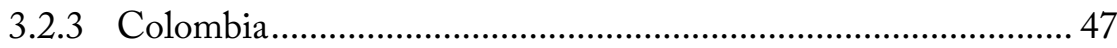

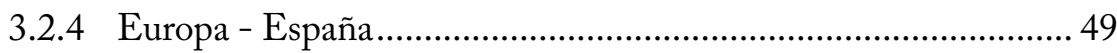

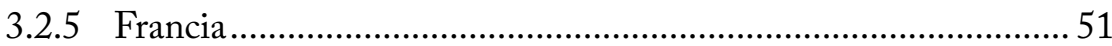

3.3 La responsabilidad de los IsP por la revelación de datos

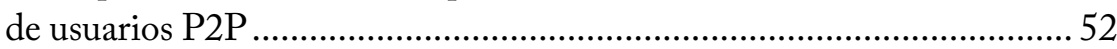

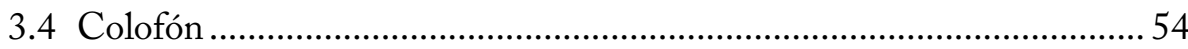

\section{Capítulo 4}

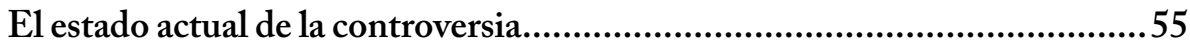

4.1 De páginas de Internet y otros usos prohibidos... ¿̇o permitidos? ........... 55

4.2 E1 estado actual de las descargas P2P en el universo jurídico ................... 60

4.3 La maldición de las leyes que sancionan las tecnologías P2P.................. 64

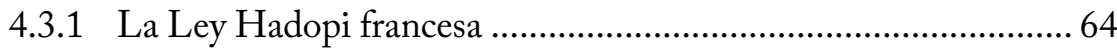

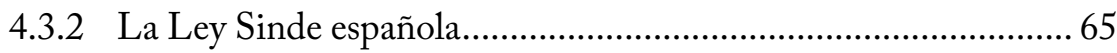

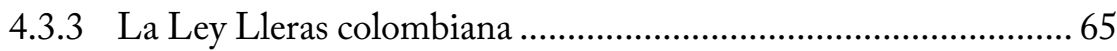

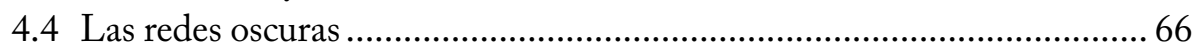

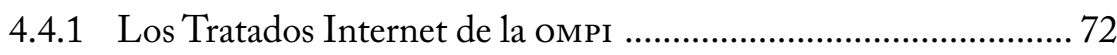

4.4.2 El fracaso de las medidas tecnológicas de protección................... 75 
4.5 La cruzada japonesa en contra de la ciberpiratería................................... 79

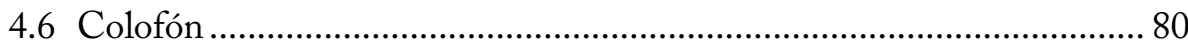

Capítulo 5

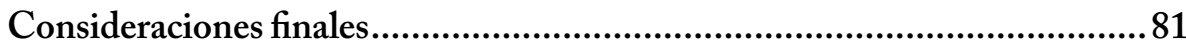

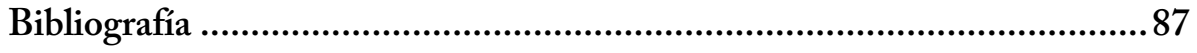

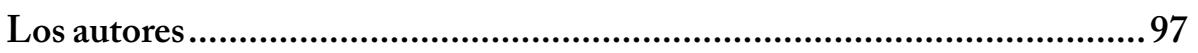





\section{Introducción}

Durante las dos últimas décadas, el mundo ha sido testigo de cómo la protección jurídica debida a las creaciones del talento humano se encuentra en crisis, dada la expansión global de las telecomunicaciones a través de Internet. Las falsificaciones o duplicaciones de los bienes protegidos siempre requirieron gran talento e inversión, ya que lograr una copia era una actividad compleja e incluso mal vista ante los ojos de la sociedad civilizada.

Con el advenimiento de las redes informáticas, así como con la posibilidad de realizar descargas directas de contenidos alojados en discos duros, servidores o, incluso, en la nube, el comportamiento social se modificó de manera abrupta, permitiéndole a cualquier internauta obtener canciones, películas, videos o software, entre otros, sin necesidad de reconocer derechos morales o patrimoniales algunos a sus creadores. A diario, billones de internautas copian y distribuyen archivos de audio, imagen y video que, en teoría, se encuentran protegidos por derecho de autor o copyright. La facilidad en el uso de las tecnologías informáticas, más una amplia oferta de programas que posibilitan realizar estas descargas de manera gratuita, le permiten a cualquier sujeto conectado a la red perpetrar tales conductas, con lo cual la industria del entretenimiento deja de ganar millones de dólares.

Esas pérdidas dieron lugar a que entidades como la Recording Industry Association of America (RIAA), la Motion Picture Association of America (MPAA) y la Canadian Recording Industry Association (CRIA) buscaran solución a este problema a través de mecanismos de protección jurídica en contra de los usuarios de estos programas, con el objeto de impedir el constante enriquecimiento de los infractores. Lastimosamente, en ocasiones, estas medidas resultaron excesivas y los procedimientos solo dieron lugar a sentimientos de rechazo por parte del público y a una mala prensa ${ }^{1}$.

${ }^{1}$ Bettig, R. "Copyright and the commodification of culture", <http://connection.ebscohost.com/c/ articles/9870815/copyright-commodification-culture>, consulta: 10 de junio del 2015. Y lo mismo sucedió con el caso Prévot, como se puede ver en: "Hadopi en Francia: multa a un hombre de cuarenta 
Dentro de tales opciones, se recurrió a la presentación de miles de demandas por millonarias indemnizaciones, para lo cual se llegó al atrevimiento de solicitar que los jueces ordenaran a los proveedores de servicios de Internet (ISP $)^{2}$ el desenmascaramiento de los números de identificación de los internautas que descargaran cierta cantidad de información en sus computadores. Esto con el propósito tanto de aplicar duras sanciones criminales como de obtener cuantiosas pretensiones, lo que después degeneró en un sinfín de situaciones anómalas que condujeron a decisiones injustas e ilógicas en contra de personas que resultaron afectadas de manera directa con tales resoluciones.

Además, comenzó a verse la necesidad de establecer mecanismos electrónicos y digitales que les permitieran a los autores obtener protección respecto de sus obras. En el caso de la música, por ejemplo, algunos discos compactos contienen un software que le impide al usuario transferir la información a cualquier clase de sistemas. En otros eventos, estos programas informáticos están atados a virus que infectan la operatividad de los computadores en caso de querer disponer de su contenido.

Por otra parte, los autores vieron en este problema una oportunidad, razón por la cual páginas como myspace.com les permitieron dar a conocer sus creaciones incluso antes de que el disco fuera objeto de comercialización. Otros decidieron realizar lanzamientos de discos, o permitieron a fanáticos de todo el mundo acceder a su música a través de conciertos en directo ofrecidos a través de streaming en páginas como youtube.com.

Es claro que lo que está en juego son millones de dólares perdidos por la industria del entretenimiento, los cuales no son debidamente canalizados a través de los conductos económicos regulares, pues estos simplemente no existen. En efecto, cualquier internauta tiene la posibilidad tecnológica de realizar una apropiación. Por ello, los afectados agotaron todos los recursos legales para acabar con páginas como Cuevana, que permiten ver series de televisión y películas de forma gratuita, sin pagar un solo centavo.

No obstante, se ha generado una especie de conciencia colectiva que afirma que la existencia de posibilidades como iTunes o Netflix, en las que se paga una tarifa mínima para tener acceso a las obras, hacen que los autores

años a pesar de ser inocente", <http://alt1040.com/2012/09/hadopi-multa-a-un-hombre-inocente>, consulta: $1^{\circ}$ de junio del 2015.

${ }^{2}$ En inglés: Internet Service Providers. 
se encuentren protegidos. Sin embargo, esto no es tan cierto como quedará demostrado en este documento, pues mientras cae un servidor, aparecen otros donde se encuentra alojada la misma información, con posibilidades infinitas de mayor descarga en un tiempo inferior. Y, se reitera, sin pagar un solo centavo.

El problema principal en esta materia tuvo su origen en los programas que usan las redes peer-to-peer $(\mathrm{P} 2 \mathrm{P})^{3}$ — v. gr., UTorrent, LimeWire, eMule, etc.-, los cuales les permiten a millones de personas en el mundo entero compartir, copiar y distribuir a diario archivos de audio, imagen y video que, por lo menos en teoría, deberían estar protegidos por la propiedad intelectual. La facilidad en el uso de este tipo de software les permite a los infractores perpetrar estas conductas de manera gratuita, pues solo basta conectar un computador a Internet para que alcancen su objetivo.

La dificultad radica en la imposibilidad de que el usuario sea identificado directamente, pues cuando este accede al sistema solo se registra la dirección de Internet (IP $)^{4}$ de su sistema operativo. Así, la dificultad de registrar quiénes y cuáles son los usuarios que comparten estas copias implica no poder sancionar las infracciones que a diario se cometen al derecho de autor. De igual manera, los creadores de los programas utilizan mecanismos como

${ }^{3}$ Para una explicación de la estructura y el funcionamiento de las redes P2P, véanse: Varela Pezzano, E. Tecnologias peer-to-peer, derechos de autor y copyright, Editorial Universidad del Rosario, Bogotá, 2009, pp. 32-46 y Sánchez Aristi, R. El intercambio de obras protegidas a través de plataformas peer to peer, Instituto de Derecho de Autor, Madrid, 2007, p. 43.

${ }^{4}$ En inglés: Internet Protocol. La IP es la “[...] dirección numérica de una computadora en Internet de forma que cada dirección electrónica se asigna a una computadora conectada a Internet y, por lo tanto, es única. La dirección IP está compuesta de cuatro octetos, como 132.248.53.10”, Rincón Cárdenas, E. Manual de comercio electrónico y de Internet, Centro Editorial Universidad del Rosario, Bogotá, 2006, p. 388. Así mismo, véase: Halabi, S. y McPherson, D. Arquitecturas de enrutamiento en Internet, Cisco Press, 2. ${ }^{\text {a }}$ ed., Madrid, 2001, pp. 52-55. Según Varela: “[...] cuando esos dígitos son asignados por el proveedor de red a un nombre de dominio, inmediatamente son transmutados a una herramienta de comercialización intelectual para quien ostente su titularidad. Esos nombres resultan ser, en últimas, los que dan lugar al empleo de denominaciones públicas o privadas de nombres comerciales o marcas [...] una dirección IP es un valor único de cuatro octetos que se expresa en notación decimal en forma de w.X.Y.z — por ejemplo, 192.74.58.306 - [...] cuando un usuario de la red solicita conectarse desde un computador a un servidor específico, el proveedor de Internet procede a consultar las bases de datos para resolver la solicitud del dominio en una dirección IP. Todo este sistema, en términos generales, se conoce como domain name system o DNs", Varela, E. “Toysareus.com: mucho más que un nombre de dominio", en: Revista Temas Jurídicos, Colegio Mayor de Nuestra Señora del Rosario, nº 18, Bogotá, 2006, p. 106. 
sobrenombres - nicknames - y contraseñas que impiden conocer con certeza la identidad del usuario ${ }^{5}$.

De esta manera, la revelación de los infractores solo ocurre cuando los proveedores del servicio de Internet dan a conocer la identidad de las direcciones IP. Sin embargo, este tipo de situaciones implica una violación directa a los derechos de hábeas data y privacidad, debido al monitoreo y descubrimiento no solo de la actividad on line, sino también de la información personal y secreta de los usuarios.

Todos estos problemas suscitados por la interacción existente entre la utilización de la tecnología, el derecho a la cultura, la protección de los derechos patrimoniales y morales de los autores, serán abordados en esta investigación, la cual tendrá una perspectiva eminentemente internacional, aunque tendrá como punto de partida el derecho colombiano. Para tal efecto, se ha previsto dividirla en cuatro partes principales. La primera de ellas tendrá como propósito presentar en qué consisten las redes $\mathrm{P} 2 \mathrm{P}$, desde su construcción electrónica, pasando por los servidores centralizados y finalizando con la posterior difuminación de la información a través de nodos descentralizados — primera, segunda, tercera generación hasta las denominadas $\mathrm{P} 4 \mathrm{P}-6$,

\footnotetext{
${ }^{5}$ Precisamente esta fue la defensa planteada en el caso The Pirate Bay, del cual se hablará con posterioridad. Esta página web fue fundada en el 2003 por la organización sueca Piratbyrån (oficina pirata). En ella es posible buscar y descargar archivos torrents organizados en diferentes categorías: audio, video, software, juegos, pornografía, etc. Para registrarse, el usuario solo requiere una dirección de correo electrónico. El 16 de febrero del 2009 se inició un juicio penal en la Corte de Distrito de Estocolmo contra los administradores del portal, por "promocionar la infracción de terceros a las leyes del derecho de autor", Corte de Distrito de Estocolmo. Caso n. ${ }^{\circ}$ B 13301-06, abr. 17/2009. Entre las distintas acusaciones se decía que The Pirate Bay era un negocio inmensamente rentable que hacía dinero ayudando a otros a violar el derecho de autor. Así mismo, "[...] el asistir a una 'puesta a disposición', violatoria de tales derechos. El abogado de la parte acusada, Per Samuelson, argumentó la famosa 'defensa King Kong”' (King Kong defense): “[...] [la] Directiva de la ue 2000/31/ce dice que aquel que proporciona un servicio de información no es responsable por la información que se transfiere. Para ser responsable, el prestador de servicios debe iniciar la transferencia. Pero los administradores en The Pirate Bay no inician las transferencias. Son los usuarios los que lo hacen y ellos son físicamente identificables. Se llaman a sí mismos con nombres como King Kong [...]". De acuerdo con las normas de procedimiento, las acusaciones deben hacerse contra un individuo al tiempo que debe haber una estrecha relación entre los autores de un delito y los que están ayudando. Aunque han existido diferentes intentos de cerrar el portal a través de la intervención de las autoridades, esta labor ha sido casi imposible pues cada vez que se intenta clausurar el sitio se replican múltiples copias en diferentes idiomas — para un ejemplo en español: $<$ https://thepiratebay.la >, consulta: $1^{\circ}$ de junio del 2015.
}

${ }^{6}$ Bettig, R. Ob. cit. 
de manera que el lector desprevenido y desinformado en la materia entienda la operatividad del sistema.

En segundo término se hará un recuento de la manera como la jurisprudencia proferida por los tribunales de justicia de todo el mundo ha tratado a los infractores, cuyas decisiones en ocasiones resultan de plano contradictorias y, en ocasiones, absurdas, pues estas se desprendieron de ilógicas demandas. Si bien al principio fue fácil imputarles responsabilidad a las empresas que usaron sistemas centralizados, con la descentralización de los nodos los afectados decidieron cargar sus pretensiones jurídicas en contra de los usuarios.

Es allí donde se plantea la premisa para la tercera parte de este escrito, pues, como ya se indicó, de manera poco convencional se planteó la posibilidad de que los proveedores de Internet revelaran a los infractores mediante el descubrimiento de la identidad de sus direcciones de IP. Esta idea, que para algunos pudo ser el mecanismo idóneo en la protección de los derechos autorales, se devolvió rauda y veloz en su contra como un bumerán. En efecto, en la mayor parte de las ocasiones implica la violación directa a los derechos de hábeas data y a la privacidad de los supuestos infractores, debido al monitoreo y descubrimiento no solo de la actividad on line, sino también de la información personal y secreta de los usuarios de las tecnologías P2P, esto sin contar con que la actual estructura lógica de las redes obstaculiza que se indemnice integralmente a quienes se ven afectados por ellas.

De esta manera, se precisará en qué consisten tales programas informáticos y se estudiarán los principales casos en los que se ha otorgado primacía al derecho a la privacidad de los usuarios $\mathrm{P} 2 \mathrm{P}$ sobre el de los titulares de derechos de autor, así como las campañas que han emprendido grandes compañías con el propósito de judicializar a los usuarios de Internet que, ante la posibilidad de descargar archivos ilegales de obras protegidas, no le pagan remuneración alguna a los autores ${ }^{7}$. De igual manera, se hará referencia a la forma como opera la responsabilidad de los isp que revelan la identidad de los usuarios que a diario descargan y comparten contenidos protegidos por el derecho de autor.

Por último, no se puede dejar de lado el hecho de que a pesar de los múltiples esfuerzos realizados por la industria para proteger a los autores de las descargas ilegales, el problema todavía existe. Más aún cuando varias

\footnotetext{
${ }^{7}$ Ricketson, S. y Richardson, M. Intellectual property: cases and commentary, Butterworths, 7.a ed., Sydney, 1998, p. 71.
} 
legislaciones han tratado de regular el tema de forma directa. Sin embargo, estas normativas han terminado cayendo por inconveniencia, falta de voluntad política o inconstitucionalidad.

Por tal motivo, la cuarta y última parte de este documento tiene como propósito presentar lo sucedido en la materia en los ordenamientos francés, español y colombiano, así como algunos de los casos que revolvieron las aguas mansas, como ocurrió con Cuevana, Blubster, Piolet y Manolito —o el caso Soto-, y The Pirate Bay. Igualmente, en qué consisten las redes oscuras, qué indican en esta materia los tratados Internet de la Organización Mundial de la Propiedad Intelectual (ompi), el fracaso de las medidas tecnológicas de protección y en qué consiste la cruzada japonesa en contra de la ciberpiratería.

La investigación que se presenta aquí es fruto del trabajo realizado durante cuatro años en desarrollo del proyecto denominado "Propiedad intelectual", dentro de la Línea de Investigación en Derecho Comercial de la Facultad de Jurisprudencia de la Universidad del Rosario (Colombia). 